\title{
Remedios secretos, drogas heroicas y medicinas de patente: una historia de la regulación de los medicamentos en Antioquia, 1900-1940
}

\author{
Secret remedies, heroic drugs, and patent medicine: a history of drug \\ regulation in Antioquia, 1900-1940 \\ Víctor Manuel García \\ Tesis de Maestría en Historia \\ Universidad Nacional de Colombia \\ Medellín, 2007 \\ victorgarcia2006@gmail.com
}

Se estudia la historia de la regulación de los medicamentos en Antioquia - región colombiana caracterizada históricamente por su vocación comercial e industrial - entre 1900 y 1940. A comienzos del siglo XX, después de décadas de libertad, la circulación del medicamento comienza a ser vigilada por las autoridades de salud pública. El proceso de normalización de su producción, prescripción y venta no fue un acontecimiento aislado, sino parte de un proyecto nacional de higienización y medicalización en el cual el tráfico indiscriminado de remedios secretos, medicinas de patente y drogas heroicas fue considerado como un peligro para la salud de la población. Las nuevas autoridades sanitarias se enfrentaron a los intereses de importadores, empíricos y boticarios, para quienes, en muchos casos, las ambiciones comerciales prevalecían sobre la salud de los consumidores. El poder médico oficial intervino ese mercado mediante prácticas nuevas como los exámenes químicos de medicamentos, las visitas a farmacias y droguerías, el ajuste de la legislación farmacéutica y la exigencia de títulos y licencias a médicos y farmaceutas. Este proceso de medicalización generó conflictos entre las autoridades sanitarias, los boticarios y los charlatanes, pero también entre funcionarios locales y del orden nacional. El proyecto regulador de la medicina instauró nuevas condiciones de cientificidad del medicamento, al tiempo que reguló el modo de promocionarlo. En la década de 1930, la expedición de licencias de circulación para las especialidades farmacéuticas fue motivo de tensiones entre los intereses de la naciente industria farmacéutica colombiana y los de la extranjera. Para las autoridades también era evidente que la regulación de los medicamentos no podía lograrse sin un control permanente de las 'drogas heroicas', pues debido al problema de la adicción, traficantes y consumidores evadían toda legalidad para procurárselas y algunos médicos fueron cómplices de las demandas de sus pacientes. Por esta razón, las autoridades sanitarias y los políticos colombianos incursionaron tempranamente en la lucha contra el tráfico y abuso de estupefacientes: entre 1928 y 1931, se desarrolló en Antioquia una de las primeras campañas contra ese tráfico. Las fuentes consultadas muestran que los medicamentos no son una mercancía trivial. Ninguna mercancía ha involucrado para su existencia un debate tan rico, a la vez político, científico, ético y económico. El proceso de regulación de los medicamentos fue fundamental para la organización de los sistemas de salud pública en Colombia porque la instauración de nuevas prácticas de higiene y de prevención de la enfermedad no podía ser eficaz si los agentes terapéuticos usados continuaban dominados solamente por intereses privados ligados al beneficio económico.

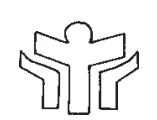

